\title{
ANALISIS KUALITAS PELAYANAN AKTA KELAHIRAN PADA DINAS KEPENDUDUKAN DAN PENCATATAN SIPIL KABUPATEN BERAU PROVINSI KALIMANTAN TIMUR
}

\author{
Oleh \\ Hermansyah \\ Staf Pemerintah Kabupaten Berau \\ Mahasiswa Program Pascasarjana Magister Terapan Ilmu Pemerintahan IPDN
}

\begin{abstract}

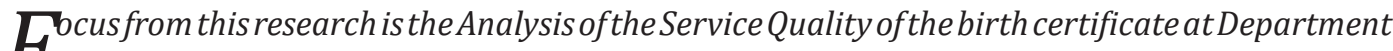
$\boldsymbol{F}$ of Population and Civil Registration of Berau Regency, the factors which influence and the efforts are being made in improving the service quality of the birth certificate at Department of Population and Civil Registration of Berau Regency.

The research use theories by Zeithaml, Valerie A, Bitner, Mary Jo related with dimension which determine the service quality, and then the factors which influence it is organization factor, apparatus factor and service system factor and the efforts to increase the service quality. The research use qualitative method with descriptive approach. In collecting the data, the researcher made observation, interview and collect the document about the Analysis of the Service Quality of the Birth Certificate at Department of Population and Civil Registration of Berau Regency.

The result of the research showed that the service quality of the birth certificate at Department of Population and Civil Registration of Berau Regency still less well. This is caused by lack of existing facilities and infrastructure such as lack of a decent and clean lounge due to the narrow and small department building, not on time in the settlement document process and lack of apparatus who serve the people.

The efforts are being made by the Department of Population and Civil Registration of Berau Regency in improving the service quality of the birth certificate among other things: 1 . Strengthen basic tasks and organization functions in cooperating with district government in serve the people. 2. Improving facilities and infrastructures by extending the department building and replacing the existing equipment with the new and the modern ones. 3. Simplify the service system with balls delivery to the districts and the villages.
\end{abstract}

Keywords: analysis of service quality, birth certificate, department of population and civil registration

\section{AbSTRAK}

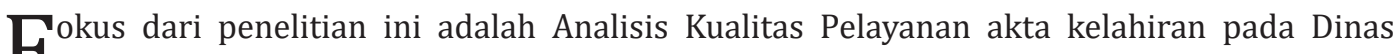
$\Gamma$ Kependudukan dan Pencatatan Sipil Kabupaten Berau, faktor-faktor yang memengaruhi serta upaya yang dilakukan dalam meningkatkan kualitas pelayanan akta kelahiran pada Dinas Kependudukan dan Pencatatan Sipil Kabupaten Berau. 
Penelitian ini menggunakan teori oleh Zeithaml, Valerie A, Bitner, Mary Jo terkait dimensi yang menentukan kualitas pelayanan, kemudian faktor yang memengaruhi yaitu faktor organisasi, faktor aparat dan faktor sistem pelayanan. dan upaya untuk meningkatkan kualitas pelayanan. Penelitian ini menggunakan metode kualitatif dengan pendekatan deskriptif. Dalam mengumpulkan data, peneliti melakukan observasi, wawancara dan mengumpulkan dokumen tentang Analisis Kualitas Pelayanan Akta Kelahiran pada Dinas Kependudukan dan Pencatatan Sipil Kabupaten Berau.

Hasil penelitian menunjukkan bahwa Kualitas pelayanan akta kelahiran pada Dinas Kependudukan dan Pencatatan Sipil Kabupaten Berau masih kurang baik. Hal ini disebabkan karena minimnya sarana dan prasarana yang ada seperti tidak adanya ruang tunggu yang layak dan bersih dikarenakan gedung kantor yang sempit dan kecil, tidak tepat waktu dalam proses penyelesaian dokumen serta kurangnya aparat dalam melayani masyarakat.

Upaya yang dilakukan Dinas Kependudukan dan Pencatatan Sipil Kabupaten Berau dalam meningkatkan kualitas pelayanan akta kelahiran antara lain: 1. Menguatkan Tugas Pokok dan Fungsi organisasi dengan bekerja sama dengan pemerintah kecamatan dalam melayani masyarakat 2. meningkatkan sarana dan prasarana dengan memperluas gedung kantor dan mengganti peralatan yang ada dengan yang baru dan modern 3. Mempermudah sistem pelayanan dengan melakukan kegiatan pelayanan jemput bola ke Kecamatan dan ke Kampung-kampung.

Kata kunci: analisis kualitas pelayanan, akta kelahiran, Dinas Kependudukan dan Pencatatan Sipil

\section{PENDAHULUAN}

Delayanan yang baik tidak terlepas dari kemampuan pemberi layanan yaitu aparatur pemerintahan. Penyelenggaraan tugas pokok dan fungsi sebagai aparatur pemerintah dalam memberikan pelayanan publik yang baik kepada masyarakat dituntut untuk memiliki sumber daya yang memadai, sikap aparatur pemerintah yang berdampak pada kualitas pelayanan yang diberikan kepada masyarakat pengguna jasa layanan.

Semenjak dikeluarkannya UndangUndang Nomor 23 Tahun 2014 tentang Pemerintah Daerah secara terus menerus meningkatkan pelayanan kepada masyarakat. Asas-asas penyelenggara pemerintahan daerah ialah pemberian otonomi luas kepada daerah diarahkan untuk mempercepat terwujudnya kesejahteraan masyarakat memulai peningkatan pelayanan, pemberdayaan dan peran serta masyarakat dalam pembangunan daerah. Salah satu tujuan dari otonomi daerah sebenarnya adalah semakin mendekatkan pelayanan kepada masyarakat.

Ada beberapa jenis pelayanan publikyang diberikan Aparatur kepada masyarakat, mulai dari urusan akta kelahiran sampai dengan urusan surat kematian atau yang dikenal dengan istilah catatan sipil. Catatan sipil juga merupakan suatu catatan yang menyangkut kedudukan hukum seseorang. Bahwa untuk dapat dijadikan dasar kepastian hukum seseorang maka data atau catatan peristiwa penting seseorang seperti perkawinan, perceraian, kelahiran, kematian, pengakuan anak dan pengesahan anak, perlu didaftarkan ke Dinas Kependudukan dan Catatan Sipil.

Pemerintah mengeluarkan Peraturan Menteri Negara Pemberdayaan Perempuan Dan Perlindungan Anak Republik Indonesia Nomor 06 Tahun 2012 tentang Pedoman Percepatan Kepemilikan Akta Kelahiran Dalam Rangka Perlindungan Anak dengan tujuan yaitu:

1. Meningkatkan pemahaman bagi seluruh unsur di masyarakat tentang pentingnya Akta Kelahiran; 
2. Meningkatkan pelayanan dalam pengurusan Akta Kelahiran; dan

3 Tersedianya kebijakan, sumber daya manusia dan sarana pendukung yang mempercepat pelayanan Akta kelahiran.

Oleh karena itu Dinas Kependudukan dan Catatan Sipil adalah suatu lembaga resmi pemerintah yang menangani hal-hal yang menyangkut peristiwa kependudukan yang sengaja diadakan oleh pemerintah, dan bertugas untuk mencatat, mendaftarkan serta membukukan selengkap mungkin setiap peristiwa penting bagi status keperdataan seseorang.

Berdasarkan observasi awal peneliti menemukan beberapa masalah terkait kualitas pelayanan akta kelahiran di antaranya:

1. Waktu pembuatan yang cukup lama, sehingga tidak sesuai dengan waktu yang telah ditentukan dari Dinas Kependudukan dan Pencatatan Sipil itu sendiri.

2. Kurangnya Petugas/aparat yang melayani pembuatan akta kelahiran pada Dinas Kependudukan dan Catatan Sipil Kabupaten Berau.

3. Minimnya Sarana dan prasarana yang ada di Dinas Kependudukan dan Catatan Sipil kabupaten berau.

4. Capaian Akta Kelahiran yang masih rendah.

Dari segi capaian akta kelahiran, menjelaskan bahwa semua kecamatan yang ada dil kabupaten berau memiliki tingkat! kepemilikan akta kelahiran kurang dari 50\%. Dari jumlah penduduk 221.835 jiwa, hanyal sekitar $43,11 \%$ atau 95.637 jiwa yang memiliki dokumen aktai kelahiran dan sekitar 56,89\% atau 126.198 jiwa yang belum/। tidak memiliki dokumen akta kelahiran.
Berdasarkan permasalahan di atas, penulis bermaksud untuk melakukan penelitian dalam menyusun tesis dengan judul: "Analisis Kualitas Pelayanan Akta Kelahiran Pada Dinas Kependudukan dan Pencatatan Sipil Kabupaten Berau"

\section{RUMUSAN MASALAH}

Berdasarkan latar belakang, di atas, maka penulis merumuskan masalah sebagai berikut. Bagaimana kualitas pelayanan akta kelahiran, Faktor-faktor apa saja yang memengaruhi kualitas Pelayanan akta kelahiran dan Bagaimana upaya yang dilakukan dalam meningkatkan kualitas pelayanan akta kelahiran pada Kependudukan dan Pencatatan Sipil Kabupaten Berau.

\section{Maksud dan TUJUAn Penelitian}

Penelitian ini dilaksanakan dengan maksud mendeskripsikan dan menganalisis tentang Kualitas pelayanan akta kelahiran, faktor yang memengaruhi kualitas pelayanan akta kelahiran serta upaya yang dilakukan untuk meningkatkan kualitas pelayanan akta kelahiran pada Dinas Kependudukan dan Pencatatan Sipil Kabupaten Berau.

\section{KERANGKA PEMIKIRAN}

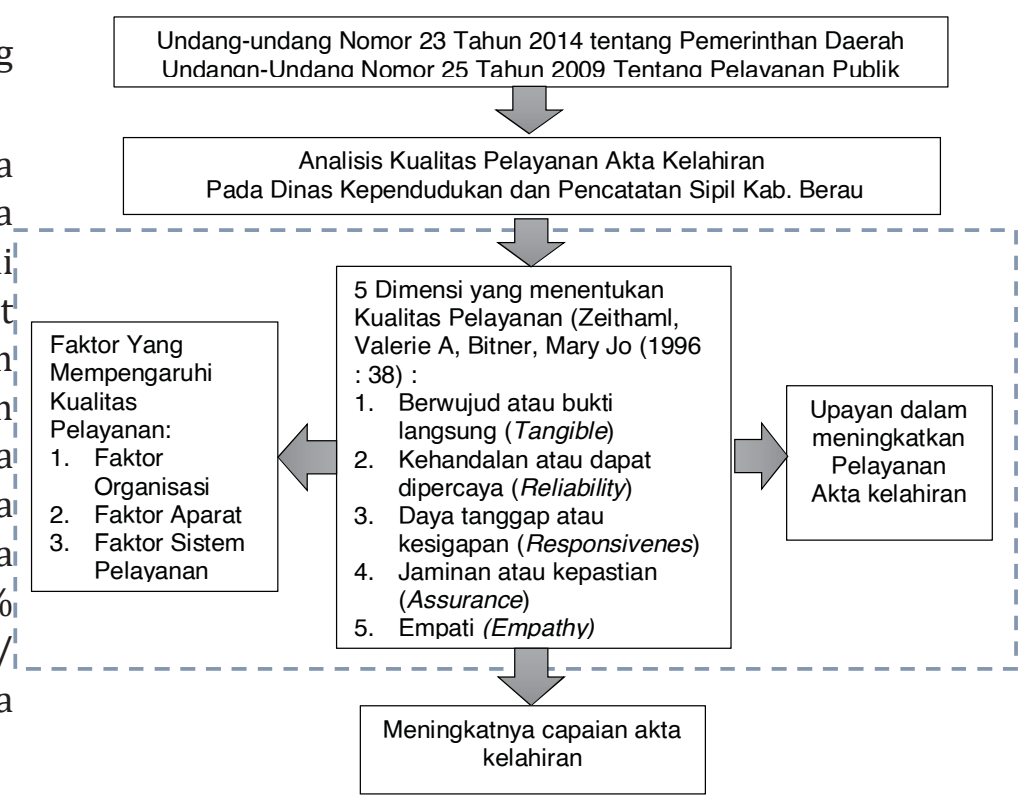




\section{METODE PENELITIAN}

Penelitian ini, penulis menggunakan desain penelitian deskriptif kualitatif (qualitative description research) yang digunakan sesuai dengan permasalahan yang akan dibahas, situasi dan kondisi dari lokasi di mana penelitian dilakukan. Tujuan penggunaan desain penelitian deskriptif pada penelitian ini adalah untuk menggambarkan masalah penelitian, khususnya mengenai masalah Kualitas Pelayanan akta kelahiran, serta kendala-kendala yang dihadapi di lapangan penelitian secara lebih mendalam dan komprehensif.

Sumber data yang digunakan dalam penelitian ini terdiri dari Person, Place dan Paper. Sumber data Person dalam Penelitian ini adalah Pemerintah Kabupaten Berau selaku pemberi pelayanan akta kelahiran dan masyarakat sebagai pengguna layanan akta kelahiran.Sumber data Place adalah di Instansi Dinas Kependudukan dan Pencatatan Sipil Kabupaten Berau. Dan untuk sumber data Paper peneliti menggunakan dokumen-dokumen perencanaan, laporanlaporan serta peraturan-peraturan terkait dengan kualitas pelayanan publik terutama dalam pembuatan akta kelahiran.

Adapun penentuan informan dalam penelitian ini dengan menggunakan Purposive sampling pada informan yang mengerti dan memahami objek yang akan diteliti. Selain itu peneliti juga menggunakan Snowballing sampling dalam menentukan informan.. Pemilihan Snowballing sampling sebagai teknik penentuan informan didasarkan pada kebutuhan penulis untuk mendalami kualitas pelayanan akta kelahiran sehingga penentuan informan juga berdasarkan tujuan informasi yang ingin didapatkan.

\section{HASIL PENELITIAN}

Berdasarkan hasil penelitian tentang Analisis kualitas pelayanan akta kelahiran pada Dinas Kependudukan dan Pencatatan
Sipil Kabupaten Berau maka dapat ditarik simpulan sebagai berikut

1. Kualitas Pelayanan Akta kelahiran Pada Dinas Kependudukan dan Pencatatan Sipil Kabupaten Berau.

Untuk menentukan kualitas pelayanan, peneliti menggunakan lima dimensi yang dikemukakan oleh Zeithaml, Valerie A, Bitner, Mary Jo yaitu Berwujud atau bukti Fisik (Tangible), Kehandalan atau dapat dipercaya (Reliability), Daya tanggap atau kesigapan (Responsivenes), Jaminan atau kepastian (Assurance) dan Empati (Empathy).

a. Berwujud atau Bukti Fisik (Tangible)

Pada Dinas Kependudukan dan Pencatatan Sipil Kabupaten Berau, Berkaitan dengan bukti fisik yang tersedia dirasa masih kurang. Berdasarkan hasil observasi di lapangan dapat dianalisis bahwa ruang pelayanan pembuatan akta kelahiran pada Dinas Kependudukan dan Pencatatan Sipil Kabupaten Berau masih jauh dari standar pelayanan seperti yang telah ditetapkan dalam Keputusan Menpan Nomor 63 Tahun 2003, prinsip-prinsip pelayanan Tetapi yang ditemukan di lapangan adalah fasilitas ruang pelayanan yang ada sangat sempit, tidak adanya ruang tunggu dan hanya disediakan kursi panjang di depan ruang pelayanan serta perlengkapan yang tersedia masih sangat kurang. selain itu letak ruang pelayanan akta kelahiran juga dirasa kurang starategis karena berada di belakang. Begitu juga dengan sarana perlengkapan kantor dalam memberikan pelayanan seperti komputer dan printer masih sangat kurang. hanya ada empat komputer dan tiga printer yang digunakan untuk mencetak dan membuat akte kelahiran dan 
dokumen lainnya terkait pencatatan sipil.

a. Kehandalan atau dapat dipercaya (Reliability)

Dari segi ketepatan waktu, Dinas Kependudukan dan Pencatatan Sipil Kabupaten Berau masih belum tepat waktu dalam menyelesaikan pembuatan akta kelahiran sesuai dengan Standar Operasional Prosedur (SOP) yang sudah ditentukan.

b. Daya tanggap atau kesigapan (Responsivenes)

Kualitas pelayanan dari segi daya tanggap pada Dinas Kedudukan dan Pencatatan Sipil Kabupaten Berau dalam hal pemberian informasi kepada masyarakat belum begitu jelas karena ada beberapa aparat yang bersikap kurang respons karena sedang sibuk sehingga memberikan tanggapan apa adanya kepada masyarakat yang membutuhkan informasi pelayanan. tetapi ada juga aparat yang dengan senang hati melayani masyarakat, mendengarkan dan menyelesaikan permasalahan yang ditemukan proses pembuatan akta kelahiran.

c. Jaminan atau kepastian (Assurance)

Dari segi prosedur pelayanan yang ada di Dinas Kependudukan dan Pencatatan Sipil Kabupaten Berau sudah sangat jelas mengenai proses dan persyaratan dalam pembuatan akta kelahiran, namun masyarakat menganggap proses tersebut masih sangat panjang dan berbelit-belit karena harus mengurus segala sesuatunya mulai dari RT, Kelurahan, Kecamatan baru kemudian ke Dinas. Prosedur dan birokrasi panjang dan berbeli-belit tersebut tentu dapat menyulitkan pemohon dalam mengurus permohonan pembuatan akta kelahiran.

c. Empati (Empathy)

Dalam memberikan pelayanan pembuatan akta kelahiran di Dinas Kependudukan dan Pencatatan Sipil Kabupaten Berau ditanamkan 3S (Senyum, Sapa, dan Salam) dari petugas atau aparatur. Akan tetapi masih saja ada beberapa pegawai yang belum maksimal dalam menerapkan hal tersebut.

Faktor-faktor memengaruhi kualitas Pelayanan akta kelahiran pada Dinas Kependudukan dan Pencatatan Sipil Kabupaten Berau:

a. Dari segi faktor organisasi, masih ada beberapa pegawai yang belum paham akan tugas pokok dan fungsinya, masih ada beberapa jabatan struktural yang penting yang masih belum terisi karena ditinggal pensiun, serta kurangnya wewenang bawahan untuk mengambil suatu tindakan yang cepat apabila ada permasalahan pelayanan yang harus ditangani dengan cepat sehingga membuat hal tersebut menjadi lambat dan harus diputuskan oleh pimpinan.

b. Dari segi faktor aparat, dilihat dari jenjang pendidikan bahwa kemampuan aparat di Bidang Pencatatan Sipil Seksi Pelayanan Kelahiran Dinas Kependudukan dan Pencatatan Sipil Kabupaten Berau sudah tergolong baik. Hal ini dibuktikan dengan tingkat pendidikan yang tinggi (sarjana) dan hanya Operator yang berstatus Tenaga Honorer saja yang berpendidikan SMA. Namun masih saja ada pegawai yang bermalas-malasan ketika tidak ada masyarakat yang sedang berususan untuk pelayanan.

c. Dari segi faktor sistem pelayanan, Dinas Kependudukan dan Pencatatan Sipil Kabupaten Berau telah memberikan 
informasi ke seluruh Kecamatan tentang prosesdur pelayanan dan syarat-syarat kepengurusan Dokumen Kependudukan, namun masih saja ada masyarakat yang kurang paham tentang proses tersebut.

Upaya Meningkatkan Kualitas Pelayanan Akta kelahiran pada Dinas Kependudukan dan Pencatatan Sipil Kabupaten Berau:

a. Penguatan Tugas pokok dan Fungsi organisasi seperti kerja sama antara Dinas Kependudukan dan Pencatatan Sipil Kabupaten Berau dengan pemerintah Kecamatan dalam memberikan pelayanan yaitu masyarakat cukup mengajukan permohonan kepengurusan akta kelahiran di Kecamatan dan pihak kecamatan yang akan mengumpulkannya dan membawanya ke Dinas Kependudukan dan Pencatatan Sipil Kabupaten Berau untuk diproses pembuatannya.

b. Upaya meningkatkan sistem pelayanan dengan mengadakan kegiatan pelayanan Jemput bola di Kecamatan dan di Kampung-kampung setiap akhir pekan. Pelayanan ini dilakukan untuk meringankan beban biaya masyarakat mengingat jarak tempuh antarkecamatan ke Kabupaten cukup jauh dan membutuhkan banyak biaya

c. Upaya peningkatan sarana dan prasarana perlengkapan pelayanan juga terus dilakukan oleh Dinas Kependudukan dan Pencatatan Sipil Kabupaten Berau seperti peningkatan Gedung kantor agar bisa lebih luas dan besar, pengadaan unit transportasi pelayanan keliling (mobil pelayanan keliling) serta mengganti perlengkapan komputer yang lama dengan yang baru yang lebih modern.

\section{SIMPULAN DAN SARAN}

\section{SimpULAN}

Berdasarkan hasil penelitian, maka dapat peneliti simpulkan sebagai berikut.
1. Kualitas Pelayanan Akta Kelahiran pada Dinas Kependudukan dan Pencatatan Sipil Kabupaten Berau masih kurang bagus dilihat dari 5 dimensi kualitas pelayanan yaitu:

2. Bukti Fisik (Tangible)

Belum tersedianya fasilitas penunjang kenyamanan pelayanan seperti ruang tunggu yang nyaman dan bersih, Ruang pelayanan yang masih sempit serta sarana perlengkapan pelayanan seperti komputer dan printer masih kurang.

a. Kehandalan (Reliability)

Dinas Kependudukan dan Pencatatan Sipil Kabupaten Berau masih kurang tepat waktu dalam proses pembuatan akta kelahiran. Tapi meski demikian aparat tetap memberikan sikap sopan dalam pelayanannya.

b Kesigapan (Responsivines)

Masih ada aparat yang kurang sigap dalam memberikan tanggapan mengenai keluhan dan kesulitan masyarakat dalam pengurusan dokumen pencatatan sipil di Dinas Kependudukan dan Pencatatan Sipil Kabupaten Berau tetapi tidak semuanya, ada juga aparat yang selalu berusaha menjelaskan berulang-ulang mengenai keluhan dan kesulitan masyarakat sampai masyarakat tersebut betul-betul paham.

c. Kepastian (Assurance)

dari segi prosedur pelayanan Dinas Kependudukan dan Pencatatan Sipil Kabupaten Berau telah menerapkan persyaratan sesuai dengan ketentuan yang ada, namun masih terkendala dengan banyaknya masyarakat yang kurang paham dengan prosesdur tersebut.

Dalam memberikan pelayanan pembuatan akta kelahiran 
ditanamkan 3S (Senyum, Sapa, dan Salam) dari petugas atau aparatur. Akan tetapi masih saja ada beberapa pegawai yang belum maksimal dalam menerapkan hal tersebut,

Faktor-faktor yang memengaruhi kualitas pelayanan akta kelahiran pada Dinas Kependudukan dan Pencatatan Sipil Kabupaten Berau yaitu faktor organisasi, faktor aparat dan faktor sistem pelayanan:

a. Dari segi faktor organisasi, masih ada beberapa pegawai yang belum paham akan tugas pokok dan fungsinya, masih ada beberapa jabatan struktural yang penting yang masih belum terisi karena ditinggal pensiun, serta kurangnya wewenang bawahan untuk mengambil suatu tindakan yang cepat apabila ada permasalahan pelayanan yang harus ditangani dengan cepat sehingga membuat hal tersebut menjadi lambat dan harus diputuskan oleh pimpinan.

b. Dari segi faktor aparat, dilihat dari jenjang pendidikan bahwa kemampuan aparat di Bidang Pencatatan Sipil Seksi Pelayanan Kelahiran Dinas Kependudukan dan Pencatatan Sipil Kabupaten Berau sudah tergolong baik. Hal ini dibuktikan dengan tingkat pendidikan yang tinggi (sarjana) dan hanya Operator yang berstatus Tenaga Honorer saja yang berpendidikan SMA. Namun masih saja ada pegawai yang bermalas-malasan ketika tidak ada masyarakat yang sedang berususan untuk pelayanan.

c. Dari segi faktor sistem pelayanan, Dinas Kependudukan dan Pencatatan Sipil Kabupaten Berau telah memberikan informasi ke seluruh Kecamatan tentang prosesdur pelayanan dan syarat-syarat kepengurusan Dokumen Kependudukan, namun masih saja ada masyarakat yang kurang paham tentang proses tersebut.

Ada beberapa upaya yang telah dilakukan Dinas Kependudukan dan Pencatatan Sipil
Kabupaten Berau dalam meningkatkan kualitas pelayanan seperti:

a. Penguatan Tugas pokok dan Fungsi organisasi seperti kerja sama antara Dinas Kependudukan dan Pencatatan Sipil Kabupaten Berau dengan pemerintah Kecamatan dalam memberikan pelayananyaitu masyarakat cukup mengajukan permohonan kepengurusan akta kelahiran di Kecamatan dan pihak kecamatan yang akan mengumpulkannya dan membawanya ke Dinas Kependudukan dan Pencatatan Sipil Kabupaten Berau untuk diproses pembuatannya.

b. Upaya meningkatkan sistem pelayanan dengan mengadakan kegiatan pelayanan Jemput bola di Kecamatan dan di Kampung-kampung setiap akhir pekan. Pelayanan ini dilakukan untuk meringankan beban biaya masyarakat mengingat jarak tempuh antarkecamatan ke Kabupaten cukup jauh dan membutuhkan banyak biaya

c. Upaya peningkatan sarana dan prasarana perlengkapan pelayanan juga terus dilakukan oleh Dinas Kependudukan dan Pencatatan Sipil Kabupaten Berau seperti peningkatan Gedung kantor agar bisa lebih luas dan besar, pengadaan unit transportasi pelayanan keliling (mobil pelayanan keliling) serta mengganti perlengkapan komputer yang lama dengan yang baru yang lebih modern.

\section{SARAN}

1. Diharapkan Dinas Kependudukan dan Pencatatan Sipil Kabupaten Berau dapat terus meningkatkan pelayanan akta kelahiran dengan memperbanyak kegiatan pelayanan Jemput Bola ke Wilayah kecamatan dan Kampung agar semua masyarakat di pelosok dapat terlayani dengan baik.

2. Dinas Kependudukan dan Pencatatan Sipil Kabupaten Berau diharapkan 
dapat lebih fokus pada peningkatan kualitas pelayanan akta kelahiran dengan bekerja sama dengan Rumah Sakit, Klinik Bersalin dan Puskesmas untuk mempercepat pemenuhan akta kelahiran anak yang baru lahir. Ini juga mempermudah masyarakat karena setelah orang tua melahirkan dan akan kembali ke rumah, anaknya sudah memiliki akta kelahiran.

3. Dinas Kependudukan dan Pencatatan Sipil Kabupaten Berau agar lebih bisa meningkatkan kualitas pelayanan melalui akses internet dengan menggunakan aplikasi dan website. Ini akan mempermudah masyarakat dalam pelayanan karena hanya tinggal mengisi format yang telah disediakan di aplikasi atau website lalu menerima nomor registrasi untuk kemudian diproses. Jadi masyarakat hanya datang ke Dinas untuk mengambil hasil sesuai dengan nomor registrasi yang telah diisi melalui aplikasi atau website.

\section{DAFTAR PUSTAKA}

Aan Komariah dan Djam'an Satori, 2010, Metodologi Penelitian Kualitatif. Bandung: Alfabeta.

Arikunto, Suharsimi. 2006, Prosedur Penelitian: Suatu Pendekatan Praktik, PTRineka Cipta. Bandung.

Boediono, 1999, "Pelayanan Prima", Penerbit Kawula Indonesia, Jakarta.

Effendy, Khasan. 2009. Otonomi Desa, CV. Indra Prahasta, Bandung.

2010. Memadukan Metode Kuantitatif dan Kualitatif, CV. Indra Prahasta, Bandung.

Hardiansyah, 2011. Kualitas Pelayanan Publik. Yogyakarta: Gava Media

Iskandar. 2008. Metodologi Penelitian Pendidikan dan Sosial (Kuantitatif dan Kualitatif). Jakarta: Gaung Persada Press.

Kaloh, J. 2007. Mencari bentuk otonomi daerah. Jakarta. Rineka Cipta.
Kotler,Philip.1997, Manajemen Pemasaran. Edisi Bahasa Indonesia jilidsatu.Jakarta: Prentice Hall.

J. Kristiadi, dkk. 1998. Pemberdayaan Birokrasi Dalam Pembangunan, Jakarta. Gramedia, Pustaka Harapan,

Miles, B. Mathew dan Michael Huberman. 1992. Analisis Data Kualitatif Buku Sumber tentang Metodemetode Baru. Jakarta: UIP.

Moenir. A.S, 2002. Manajemen Pelayanan Umum di Indonesia. Jakarta: PT. Bumi Aksara.

Moenir, A.S. 2006. Manajemen Pelayanan Umum di Indonesia. Jakarta: Bumi Aksara.

2010. Manajemen Pelayanan Umum Di Indonesia. Jakarta: Bumi Aksara.

Pamudji, 1994. Profesionalisme Aparatur Negara dalam Meningkatkan Pelayanan dan Perilaku Politik Publik. Jakarta: Widya Praja.

Patton, Sawicki. 1991. Basic Methods of Policy Analysis and Planning. Prentice Hall.

Ratminto, dan Atik Septi Winarsih. 2005. Manajemen Pelayanan. Yogyakarta:Pustaka Pelajar.

Sampara Lukman. 2000. Manajemen Kualitas Pelayanan, Jakarta: STIALAN Press.

Sampara Lukman \& Sugiyanto: 2001. Pengembangan Pelaksanaan Pelayanan Prima. Buku Ajar Diklatpim Tingkat III

Sinambela, Lijan Poltak, dkk, 2011: Reformasi Pelayanan Publik. Jakarta: PT. Bumi Aksara.

Siswosoediro, H, S. 2008. Buku Pintar Pengurusan Perizinan dan Dokumen. $\mathrm{P}$ a $\mathrm{n} \mathrm{d} \mathrm{u}$ a $\mathrm{n}$ Pelaku Usaha dan Masyarakat Umum. Jakarta: Visi Media Pustaka.

Robbins, P. Stephen and Timothy A. Judge, 2009, Organizational Behavior, $13^{\text {th }}$ Edition, Pearson Education, lnc, Upper Saddle River, New Jersey, pp. 209- 586.

Sugiyono, 2009. Memahami Penelitian Kualitatif. CV Alfabeta. Bandung.

2010. Metode Penelitian Kuantitatif Kualitatif dan R\&D. CV Alfabeta. Bandung. 
Sugiyono. 2011. Metode Penelitian Kuantitatif kualitatif dan R\&D. Bandung: Alfabeta.

Susanto. 2006. Metode Penelitian Sosial. Surakarta: UNS Press.

Thoha, Miftah. 2008. Perilaku Organisasi: Konsep Dasar dan Aplikasinya. Jakarta. Raja Grafindo Persada.

Tjiptono, Fandi dan Diana Anastasia, 2000. Total Quality Management, Yogyakarta: Andi 2004, Edisi Ke-empat. Prinsip-prinsip Total Quality Service (TQS). Yogyakarta: Andi

Zeithaml, Valerie A, Bitner, Mary Jo, 1996, Service Marketing, Mc.Graw Hil (International Edition).

\section{Peraturan Perundang-Undangan}

Undang-Undang Nomor 23 Tahun 2014 tentang Pemerintahan Daerah.

Undang-Undang Nomor 23 Tahun 2002 tentang Perlindungan Anak.
Undang-Undang Nomor 23 Tahun 2013 Perubahan atas Undang-Undang Nomor 23 tahun 2006 tentang Administrasi Kependudukan dan Catatan Sipil.

Undang-undang Republik Indonesia Nomor 25 tahun 2009 tentang Pelayanan Publik

Peraturan Menteri Negara Pemberdayaan Perempuan Dan Perlindungan Anak Nomor 6 Tahun 2012 tentang Pedoman Percepatan Kepemilikan Akta Kelahiran

Keputusan Menteri Pendayagunaan Aparatur Negara Nomor 63 Tahun 2003 tentang Pedoman Pelayanan Publik

Peraturan Daerah Kabupaten Berau Nomor 30 Tahun 2011 tentang Penyelenggaraan Administrasi Kependudukan dan Catatan Sipil.

Renstra Dinas Kependudukan dan Catatan Sipil Kabupaten Berau Tahun 2016-2021 